\title{
Finite Element Simulation and Experimental Validation of Manufacturing Process for Alternator Housing
}

\author{
Kyu-Taek Han \\ Department of Mechanical Engineering, Pukyong National University, Busan, 608-739, Korea \\ *Corresponding Author: kthan@pknu.ac.kr
}

Copyright (C) 2013 Horizon Research Publishing All rights reserved.

\begin{abstract}
For the development of the manufacturing process of alternator housing, finite element simulation is applied. In recent years, automobile parts are required to be light and have high strength. The control of casting defects is important in die casting process. However, it has usually been depended on the experience of the foundry engineer. The die casting process was used to manufacture automotive alternator housings. In this paper, the die characteristics of alternator housing with the HPDC(High Pressure Die Casting) process were investigated using computer simulations. Through the simulations using the commercial software, the filling pattern and product defects could be confirmed. The computer simulation results of filling behavior were reflected to the optimal design of the alternator housing. The analysis results obtained from the filling behavior of casting process agreed with experimental results.
\end{abstract}

Keywords Alternating housing, Manufacturing Process, Finite Element Simulation, Die Casting

\section{Introduction}

Recently the requirement of light weight and high performance automobiles has been increased. The weight of the automobile is very important from the viewpoint of fuel consumption and traveling performance. Consequently, lightweight materials such as aluminum, magnesium, and titanium comes to be more important. Optimal design techniques, material techniques, process design for parts and die design techniques need to be developed for light weight automobile parts. Die casting, melted metal poured into the die cavity in conditions high speed and high pressure, is one of the best methods. Generally the die casting is considered as an appropriate forming process to manufacture the products in which complex shapes or precision surfaces are desired. The die casting process is divided into the filling process and the solidification process. The die casting process has a series of complex temperature changes.
Incidentally, the research by experiment must have limits because it proceeded in the die cavity which is shut.[1-7] But the research which predicts and prevents the defects of products and dies is still in its early stage. Few papers[8-10] have been found in the literature, because of insufficient data of the precision manufacturing technology in die casting. Therefore in this study, the filling and solidification process were predicted using computer simulation and its results were reflected in the die design and the process design as a previous step for the development of the precision die of an automotive housing.

\section{Simulation of Die Casting}

\subsection{Governing Equations}

The flow of fluid and the heat transfer phenomenon in the governing equation are represented by the mass, momentum, and the rule of energy conservation. The governing equations used for the flow and the solidification of three dimensional incompressible flow are expressed by Eqs.(1)-(4), continuity equation(1), energy equation(2), volume of fluid(3), and Navier-Stokes equation(4). Equation(5) shows the finite differential equation for the filling.

\subsubsection{Continuity Equation}

$$
\frac{\partial u}{\partial x}+\frac{\partial v}{\partial y}+\frac{\partial w}{\partial z}=0
$$

2.1.2. Energy Equation

$$
\begin{aligned}
& \rho c \frac{\partial T}{\partial t}=\frac{\partial}{\partial x}\left(K \frac{\partial T}{\partial x}\right)+\frac{\partial}{\partial y}\left(K \frac{\partial T}{\partial y}\right) \\
& +\frac{\partial}{\partial z}\left(K \frac{\partial T}{\partial z}\right)
\end{aligned}
$$

2.1.3. Volume of Fluid 


$$
\frac{\partial F}{\partial t}=u \frac{\partial F}{\partial x}+v \frac{\partial F}{\partial y}+w \frac{\partial F}{\partial z}
$$

2.1.4. Navier-Stokes Equation

$$
\begin{aligned}
& \frac{\partial u}{\partial t}+u \frac{\partial u}{\partial x}+v \frac{\partial u}{\partial y}+w \frac{\partial u}{\partial z} \\
& =-\frac{1}{\rho} \frac{\partial p}{\partial x}+v \vec{\nabla}^{2} u+g_{x} \\
& \frac{\partial v}{\partial t}+u \frac{\partial v}{\partial x}+v \frac{\partial v}{\partial y}+w \frac{\partial v}{\partial z} \\
& =-\frac{1}{\rho} \frac{\partial p}{\partial y}+v \vec{\nabla}^{2} v+g_{y} \\
& \frac{\partial w}{\partial t}+u \frac{\partial w}{\partial x}+v \frac{\partial w}{\partial y}+w \frac{\partial w}{\partial z} \\
& =-\frac{1}{\rho} \frac{\partial p}{\partial z}+v \vec{\nabla}^{2} w+g_{z}
\end{aligned}
$$

2.1.5. Governing Differential Equation(GDE)

$$
\begin{aligned}
& \frac{\partial}{\partial t}(\rho \phi)+\frac{\partial}{\partial x_{j}}\left(\rho u_{j} \phi\right) \\
& =\frac{\partial}{\partial x_{j}}\left(\Gamma_{\phi} \frac{\partial \phi}{\partial x_{j}}\right)+S_{\phi}
\end{aligned}
$$

where $\mathrm{u}, \mathrm{v}, \mathrm{w}$ are the direction velocity, is the kinematic viscosity, is the fluid viscosity, $\mathrm{g}$ is the gravity acceleration, $\mathrm{p}$ is the pressure, and $\mathrm{F}$ is the volume rate of fluid.

\subsection{Modeling and Preprocessor}

Figure 1 shows the shape model of a motor housing and is expressed using the Unigraphics as the STL file format for recognition in commercial $\mathrm{S} / \mathrm{W}$ MAGMAsoft. In the figure $\mathrm{A}$ is inlet and has $41181.65 \mathrm{~mm}^{3}$ in volume, $\mathrm{B}$ is gate and has $179335.9 \mathrm{~mm}^{3}$ in volume, $C$ is ingate and has $300.7931 \mathrm{~mm}^{3}$, and $\mathrm{D}$ is cast and has $105311.3 \mathrm{~mm}^{3}, \mathrm{E}$ and $\mathrm{F}$ are the overflow 1 and 2 and have $171.49 \mathrm{~mm}^{3}, 3887.85 \mathrm{~mm}^{3}$ in volume respectively. The motor housing shape model needs the dimensional accuracy of the average thickness $2.5 \sim 3.5$ within the maximum circularity 0.1 based on an inner diameter 100 .

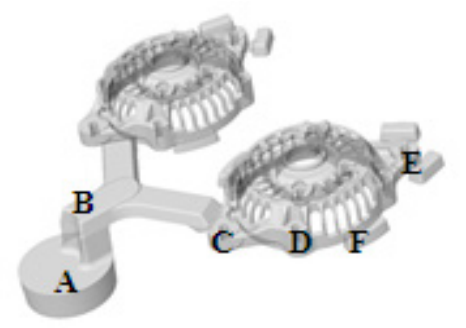

Figure 1. 3D Solid model of alternator housing

\subsection{Input of Analysis Condition}

The material of the motor housing is ADC12 and the physical properties and chemical composition for the analysis are expressed in Tables 1 and 2. The material for the die is STD61 and water is used in cooling the channel. The melting metal, after the die is closed, is poured and we add pressure after the filling of melting metal for the strength of casting and the removal of contraction hole during the solidification process. The die is opened and products are ejected after the completion of the cast solidification, and the die is shut again after spraying the surface of the die for the next cycle to begin.

Table 1. Physical properties of ADC12 alloy

\begin{tabular}{|c|c|c|}
\hline Properties & Unit & Value \\
\hline Initial Temp. & ${ }^{\circ} \mathrm{C}$ & 660 \\
\hline Latent Heat & $\mathrm{kJ} / \mathrm{kg}$ & 514.2 \\
\hline Tliq & ${ }^{\circ} \mathrm{C}$ & 614 \\
\hline Tsol & ${ }^{\circ} \mathrm{C}$ & 555 \\
\hline
\end{tabular}

Table 2. Chemical composition of ADC12 alloy

\begin{tabular}{|c|c|c|c|c|c|c|c|c|}
\hline $\mathrm{Cu}$ & $\mathrm{Si}$ & $\mathrm{Mg}$ & $\mathrm{Zn}$ & $\mathrm{Fe}$ & $\mathrm{Mn}$ & $\mathrm{Ni}$ & $\mathrm{Sn}$ & $\mathrm{Al}$ \\
\hline 3.1 & 11.5 & 0.3 & 0.8 & 0.9 & 0.4 & 0.3 & 0.2 & $\mathrm{R}$ \\
\hline
\end{tabular}

\subsection{Structure of the Alternator Housing Die}

Figure 2 shows the basic structure of the alternator housing die. The existing casting technique is problematic for the production of the alternator housing products in that it cannot guarantee accuracy within the maximum circularity 0.1 based on an inner diameter 100 . For this reason, special purpose machines or general purpose lathes are required for machining alternator housings.

To solve the problem we designed the die after modifying the machine structure to make possible the ejecting in a fixed part.

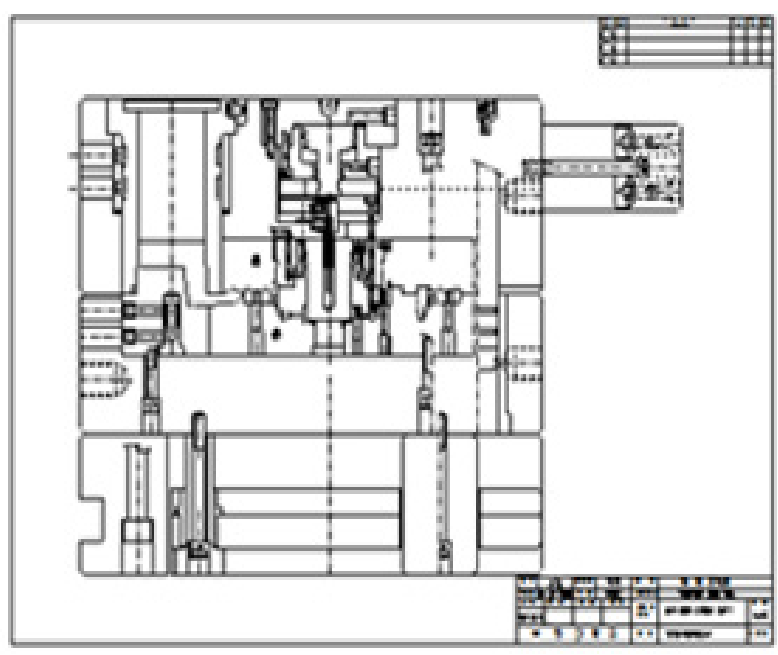

Figure 2. Assembly drawing of the alternator housing die 
Figure 3 expresses the forming process of the alternator housing step by step.

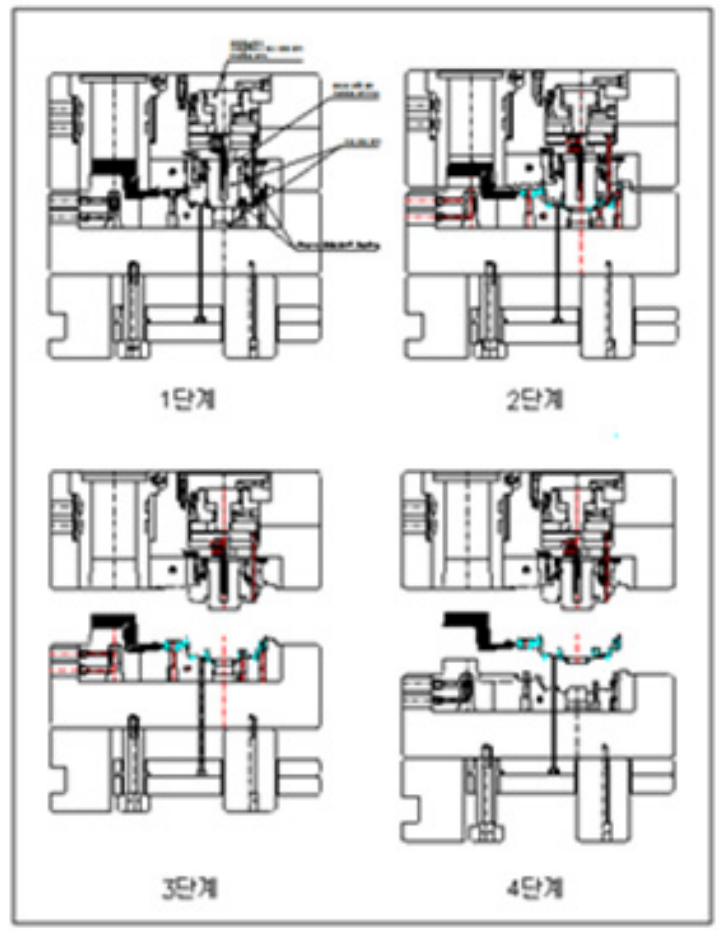

Figure 3. Sequential steps of the die casting process

\section{Results and Discussions}

\subsection{Filling Analysis}

The overall filling behavior of molten metal is shown in Figure 4. The molten metal fills in a constant filling pattern due to the housing's uniform thickness design of $2.5 \mathrm{~mm}$ to $3.5 \mathrm{~mm}$ as was considered in the initial form design. The molten metal was filled uniformly in a geometrically balanced alternator die. Figure 5 shows a good filling behavior where the temperature doesn't drop below the liquid state line $\left(\mathrm{Tliq}=614^{\circ} \mathrm{C}\right)$, because of showing filling and temperature balance in a geometrically balanced runner system with two cavities.

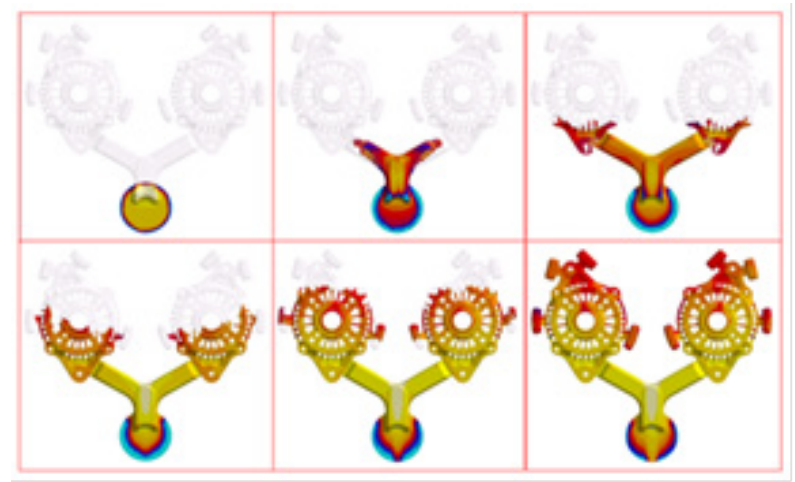

Figure 4. Filling behavior of alternator housing

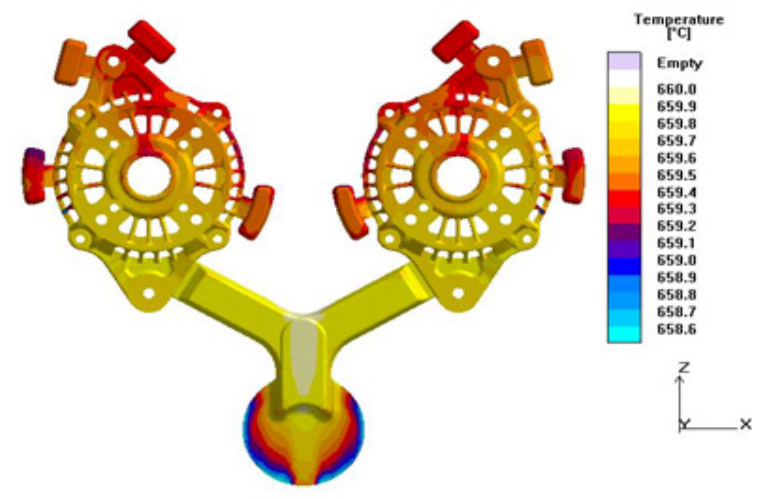

Figure 5. Temp. distribution of alternator housing

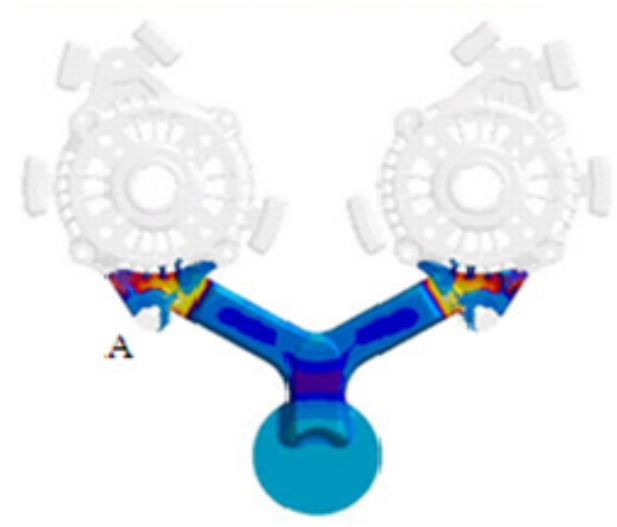

Figure 6. Filling behavior of alternator

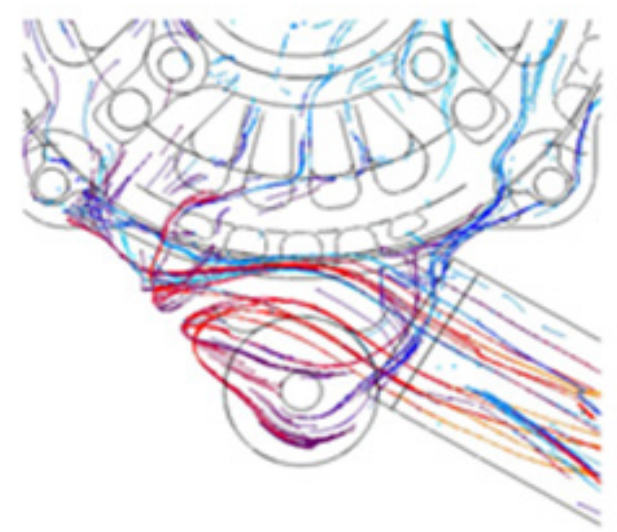

Figure 7. Enlarged diagram of "A" in Figure 6

Figure 6 and Figure 7 present the time about $50 \%$ of molten metal fills housing die after the ingate is filled. The melting head collides near mark A, ingate, and it forms a vortex, and because of this, defects occurred in the part. This is considered to be because the flow of molten metal rotates at part $\mathrm{A}$. The injection pressure at the ingate, as a result, is reduced and the cold shut by temperature drop and air porosity is predicted. This filling phenomenon is cause by complicated interaction between molten metal and die. To avoid this, the parting line of the die was moved and added the overflow at the A part. By modifying the die based on the result, the better forming was conducted and 
this is in good accord with the experimental results in a later section.

\subsection{Final Die Design}

Figure 8 shows the die modified with the overflow to remove the vortex of part A in Fig. 6, in accordance with the simulation results of the first design. Figure 9 shows the die made by the second design. Figure 10 shows the product formed by the second design. The filling behavior agreed with the simulation results and additional machining wasn't needed after ejecting.

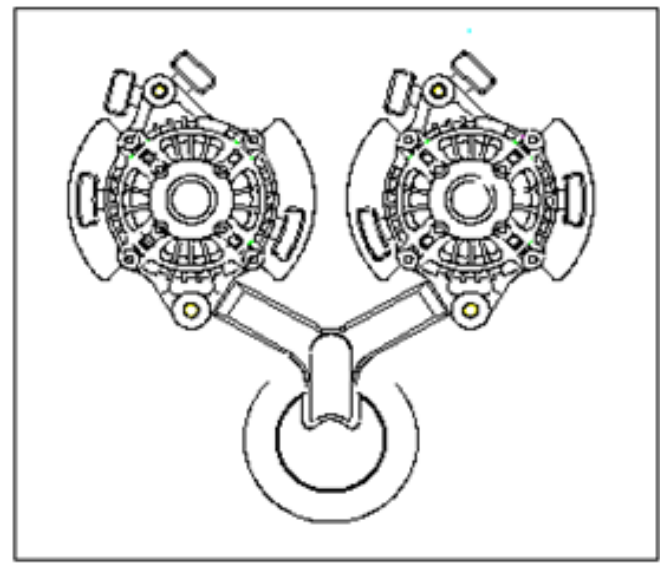

Figure 8. Modified design of alternator housing die

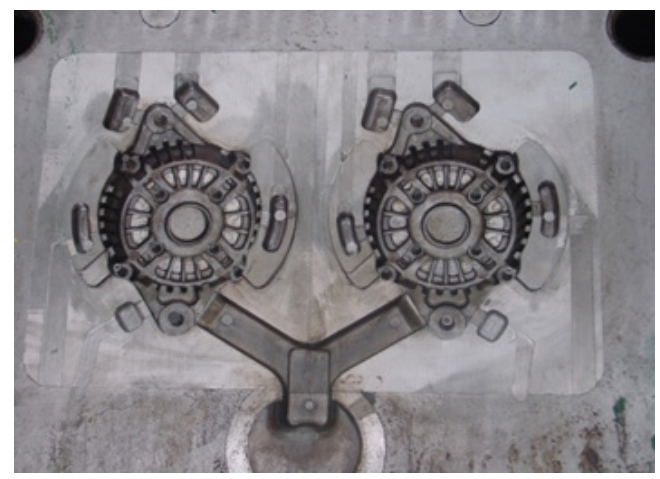

Figure 9. Photo of alternator housing die

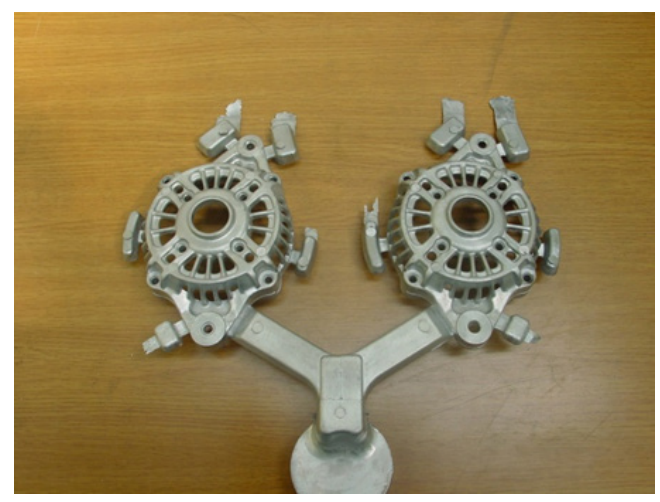

Figure 10. Photo of alternator housing cast

\section{Conclusion}

In this study, we confirmed the filling pattern and product defects, and verified them using the commercial software, MAGMAsoft for the optimal design of the alternator housing. It is expected the effectiveness of a fixed quantity connected directly with it, will increase, such as the reduction of defects, quality enhancement, and a productivity increase due to this research results.

The conclusions of this research can be summarized as follows, first the overall filling pattern expressed constant flow and the filling analysis results are agreed to the filling pattern of product, and then the defects prediction and the analysis of the product and the die can be done using the computer simulation of the first die design, finally the good casting product with appropriate filling pattern can be manufactured by the application of a new die design mechanism for the maximum circularity 0.1 of product.

\section{Acknowledgements}

This study was partially supported by the grant No.2013-I-06 from the Leaders in INdustry-University Cooperation(LINC) program of the Ministry of Education at Pukyong National University.

\section{REFERENCES}

[1] J. S. Kim, T.W. Lim, Novel Techniques of High Pressure Die Casting, J. of the Korean Foundrymen's Society, Vol.18, No.3, 228-233, 1998.

[2] C. C. Tai, J. C. Lin, The Optimal Position for the Injection Gate of a Die-casting Die, J. of Materials and Technology, 86, 87-100, 1999.

[3] C. H. Lee, J. K. Choi, Die Design for High Pressure and Casting Process Analysis, the Korean Foundrymen's Society, Vol.20, 400-406, 2000.

[4] C. G .Kang, Y. I. Son, and S. W. Youn, Experimental Investigation of Semi-solid Casting and Die Design by Thermal Fluid-solidification Analysis, J. of Materials and Technology, 113, 251-256, 2001.

[5] N. Nishi, High Pressure Die Casting Process, , J. of the Japan Foundrymen's Society, Vol.71, 62-70, 1999.

[6] N. Nishi, Die Casting Technology of 21th Century, J. of the Japan Foundrymen's Society, Vol.73, 32-33, 2001.

[7] M. R. Barone, D. A. Caulk, Analysis of Liquid Metal Flow in Die Casting, Int. J. of Engineering Science, Vol. 38, 1279-1302, 2000.

[8] K. Y. Kim, Recent Trends on the Application of Computer to Solidification Processing, J. of the Korean Foundrymen's Society, Vol.11, No.4, 276-282, 1991.

[9] Y. Otsuka, Optimization of Light Weight Casting Design 
and Production by Application of CAE, J. of the Japan Foundrymen's Society, Vol.67, 868-874, 1995.

[10] I. Takahashi, Introduction to Conventional Casting CAE system, J. of the Japan Foundrymen's Society, Vol.73, 482-488, 2001. 